\title{
Punctuated equilibrium in a non-linear system of action
}

\author{
Jos Timmermans
}

Published online: 12 September 2008

(C) The Author(s) 2008. This article is published with open access at Springerlink.com

\begin{abstract}
Coleman's equilibrium model of social development, the Linear System of Action, is extended to cover the dynamics of societal transitions. The model implemented has the characteristics of a dissipative system. A variation and selection algorithm favoring the retention of relatively dependent actors forces the system away from equilibrium, while exchange of control, according to Coleman the driving force behind social action, accounts for dissipation, pulling the social system back to equilibrium. This Non-linear System of Action self-organizes into a critical state, as confirmed by the robust power law distribution of exchange of control for a wide range of model sizes. Related punctuated equilibrium dynamics and structural change are of special interest, as these are closely connected to hypotheses on social dynamics developed in the literature on societal transitions.
\end{abstract}

Keywords Punctuated equilibrium - Self-organized criticality · Societal transition · Social change $\cdot$ Coleman $\cdot$ Social simulation

\section{Introduction}

Transitions are structural innovations of societal systems in reaction to wicked problems threatening development (Rotmans 2005; Rotmans et al. 2001; Van der Brugge et al. 2005; Geels and Kemp 2000). Transition studies offer an analytical framework for describing and explaining the dynamic behavior of societal systems, such as transport, energy supply, agriculture, and water management. The underlying transition dynamics are complex interaction processes between markets,

J. Timmermans $(\bowtie)$

Faculty of Social Sciences, Dutch Research Institute for Transitions, Erasmus University Rotterdam, P.O. Box 1738, 3000 DR Rotterdam, The Netherlands

e-mail: timmermans@fsw.eur.nl

url: http://www.eur.nl/fsw/staff/homepages/timmermans/ 
networks, institutions, technologies, policies, individual behavior and autonomous trends in the economic, ecological, socio-cultural and institutional domain. From a complex adaptive systems perspective, transitions are system transformations between two temporal dynamic equilibrium states. In between there is a period of rapid change during which the system undergoes irreversible re-organization (Rotmans 2005). According to Rotmans (2005) and Rotmans et al. (2001) the general pattern of evolution of a societal transition can be divided in four phases, predevelopment, take-off, acceleration and stabilization. In the pre-development phase, the system dynamics do not change visibly. In the take-off the structure of the system begins to change, while in the acceleration phase structural transformation takes place. In the stabilization phase the system reaches a new dynamic equilibrium.

The conceptualization of societal transitions in transition studies has much in common with a class of revolutionary change theories based on the punctuated equilibrium paradigm postulated by Eldredge and Gould (Gould and Eldredge 1977; Eldredge and Gould 1972). The punctuated equilibrium paradigm is used in different strands of the social sciences; with reference to Eldredge and Gould and explicit use of the concept of punctuated equilibrium, Castells (1996) analyses the rise of the network society at the end of the twentieth century as '.. one of these rare intervals in history...', similarly, Baumgartner and Jones (Jones and Baumgartner 2005; Baumgarter and Jones 1993) apply the concept of punctuated equilibrium to explain the alternation of long periods of stability and rapid change in American policy domains. Transition studies can be positioned in between the work of Castells, who analyses structural change in social systems and Baumgartner and Jones who remain at the level of the policy system. Transition studies aim to explain stability and structural change in functional sub-systems supplying an important function to a society, like energy supply, water resources management or mobility and transport (Rotmans 2005; Rotmans et al. 2001; Van der Brugge et al. 2005).

Gersick (1991) confronts the Darwinian concept of incremental cumulative change with the punctuated equilibrium paradigm through exploring six empirically derived theories from psychology, group dynamics, organization science, biology and self-organizing systems. Gersick compares these six theories using five relevant concepts from the punctuated equilibrium paradigm; general description of the punctuated equilibrium model, how punctuated equilibrium models differ from traditional counterparts, the concept of deep structure, the concept of equilibrium periods and the concept of revolutionary change. In Table 1 the analyses of Gersick is complemented and transition studies is positioned in the field of theories working from the punctuated equilibrium paradigm. Parallels are especially strong in the conceptualization of a deep structure, the alternation of stability and change and the description of revolutionary periods. Deep structure is of specific interest because both Gersick and transition studies relate periods of revolutionary change to changes in deep structure. In transition studies deep structure is described in terms of the dominant practices, culture and structure of the regime, the dominant way in which a societal need is fulfilled (Rotmans 2005).

Bak and Sneppen (1993) were the first to develop theoretical support for the punctuated equilibrium hypotheses of Eldredge and Gould in their simple model 
Table 1 Transition studies and the punctuated equilibrium paradigm (after Gersick 1991)

\section{Commonalities in the description of the punctuated equilibrium paradigm}

Six theories: Systems evolve through the alteration of periods of equilibrium, in which persistent underlying structures permit only incremental change, and periods of revolution, in which these underlying structures are fundamentally alter.

Transition Studies: transitions develop according to four phases, pre-development, take-off, acceleration and stabilization. In the pre-development phase, the system dynamics do not change visibly. In the takeoff the structure of the system begins to change, while in the acceleration phase structural transformation takes place. In the stabilization phase the system reaches a new dynamic equilibrium (Van der Brugge and Rotmans 2007; Martens and Rotmans 2005).... we see a transformation from slow to quick development and instability, reverting at last to relative stability (Rotmans et al. 2001).

Commonalities in the description of the differences between punctuated equilibrium and traditional models

Six theories: Systems do not evolve through a gradual blending from one state to the next. Systems' histories are unique. They do not necessarily evolve from lower to higher states, through universal hierarchies or stages, or toward pre-set ends.

Transition studies: A transition is no fixed pattern, nor a blue print, it is not uniform and deterministic there are large differences in the rate and scale of change. Rather transitions are possible development paths (Rotmans 2005).

\section{Communalities in the concept of Deep Structure}

Six theories: Deep structure is a network of fundamental 'choices', of the basic configuration in to which a system's units are organized, and the activities that maintain both this configuration and the system's resource exchange with the environment. Deep structure in human systems is largely implicit. Transition Studies: ... where the structural character of society transforms (Martens and Rotmans 2005).... in which society changes in a fundamental way (Rotmans et al. 2001). Its internal dynamics are deeply embedded in social interactions that are consequently difficult to change.... The system undergoes irreversible reorganization... (Van der Brugge et al. 2005).... new structures emerge and existing structures are broken down (Van der Brugge and Rotmans 2007).... there are patterns of institutions, artefacts, rules and norms assembled and maintained to perform economic and social activities which is referred to as the regime (Smith et al. 2005). ... transitions are system transformations... (Van der Brugge and Rotmans 2007)

Communalities in the concepts of equilibrium periods

Six theories: During equilibrium periods, systems maintain and carry out the choices of their deep structure. Systems make adjustments that preserve the deep structure against internal and external perturbations, and move incrementally along paths built into the deep structure. Pursuit of stable deep structure may result in behavior that is turbulent on the surface.

Transition Studies: ... the regime grows 'critical' and innovations start acting as perturbations of the status quo (Van der Brugge and Rotmans 2007). ... transitions are system transformations between to temporal (dynamic) equilibrium states (Van der Brugge and Rotmans 2007). ...the regime is able to maintain and reproduce its internal dynamics (Van der Brugge and Rotmans 2007).... the new regime settles down. Transformation processes turn into optimization processes. Regime dynamics now are equilibrium dynamics (Van der Brugge and Rotmans 2007).

Communalities in the concepts of revolutionary periods

Six theories: Revolutions are relatively brief periods when a system's deep structure comes apart, leaving it in disarray until the period ends, with the 'choices' around which a new deep structure forms. Revolutionary outcomes, based on interactions of systems' historical resources with current events, are not predictable; they may or may not leave a system better off. Revolutions vary in magnitude.

Transition Studies: ... visible structural changes take place through an accumulation of socio-cultural, ecological and institutional changes... (Rotmans et al. 2001).... in between there is a period of rapid change... (Van der Brugge and Rotmans 2007)... we see a transformation from slow dynamics to quick development and instability... (Rotmans et al. 2001).... in which the speed of social change decreases and a new dynamic balance is reached (Martens and Rotmans 2005). 
of evolution. Bak and Sneppen relate punctuated equilibrium dynamics to Self Organized Criticality (SOC), as introduced by Bak et al. (1988). They define this self-organized critical state as a global attractor for the system as it is not dependent on the initial conditions and hence is self-organized. ${ }^{1}$ Where Gersick infers that punctuated equilibrium dynamics are related to a deep structure stabilizing the system in periods of equilibrium and re-structuring in periods of revolutionary change, Bak and Sneppen relate punctuated equilibrium to SOC, signified by power law distributions of the outputs of these systems (Bak et al. 1988; Bak and Sneppen 1993). SOC and power law distributions have since been related to many natural phenomenon like earthquakes, sand and rice pile dynamics, super conduction and droplet formation (Field et al. 1995; Plourde et al. 1993; Held et al. 1990; Jaeger et al. 1989) while punctuated equilibrium and deep structure approaches mainly continued in the social and management sciences (Gersick 1991).

Because of these diverging traditions the relation between SOC and deep structure in relation to punctuated equilibrium remained unspecified. Except from some recent contributions in social network analyses, where SOC and power laws are found to characterize empirical and simulated social networks (Whitmeyer and Yeingst 2006; Albert and Barabási 2002; Watts 2002). For transition studies, both the quantitative interpretation of punctuated equilibrium dynamics in term of the (power law) distribution of the speed and size of change as used by Bak and Sneppen and the qualitative interpretations in term of deep structure as introduced by Gersick are of interest.

The computational approach to societal transitions developed in this article, starts from the punctuated equilibrium paradigm and focuses on both the dynamics of such a model and the identification of structural change. The Social Theory of James S. Coleman (1990) is used as a starting point. This theory is a well established social theory, addresses social development of which societal transitions are a specific instance and is widely applied in sociology and policy analysis (Timmermans and Beroggi 2004; Timmermans 2004; Schouten et al. 2001; Stokman and Berveling 1998; Stokman and Zeggelink 1996; Pappi and Knoke 1991) and has a quantitative implementation, the Linear System of Action (LSA), that seems promising for our purpose.

In the remainder of this paper first a model of social dynamics showing punctuated equilibrium dynamics and self-organized criticality is developed and some structural characteristics of this model, related to the regime concept of transition studies, are investigated. Finally promising directions for further theoretical research and practical applications of the model in further developing the field of transition management are identified.

\section{The linear system of action}

Coleman's Social Theory explains social development as the result of exchange of control over issues between actors and belongs to the group of social theories that

\footnotetext{
${ }^{1}$ In a later paper by Tamarit et al. (1998) the Bak Sneppen model, like the onset of chaos in one dimensional maps, is proven to show weak dependence on initial conditions. This property in connected to the fractal nature of the self-organised attractor and is believed to be crucial for the evolutionary process.
} 
apply exchange theorizing and rational choice theory (Turner 1998). According to Coleman, any social system exists of actors and issues over which they exercise control and in which they have some interest (Coleman 1990). It is each actor's interest in issues under another's control that lead purposive actors (Weber 1958 [1904]) to engage in interactions involving exchanges of control. In these transactions actors maximize their control over issues of their interests. According to Coleman these profitable exchanges of control are the primary explanatory factor for social development. To illustrate the argumentative structure embedded in Coleman's Social Theory we next present an example from decision making, where decision makers are characterized by their interest in and control over an issue and the decision is framed in terms of exchange of control.

In decision making on the construction of a power plant, the particular electricity company that wants to invest might depend on the banks to finance the plant while at the same time it needs a license from the water authority for cooling water, the provincial government for spatial planning, the local government for environmental and building licenses and the national government and local fire department for safety requirements. Furthermore, the location of the plant in the national electricity network managed by a national authority is relevant, two or three local and regional environmental groups have concerns, a national action group against nuclear energy fears the nuclear option while a local organization of farmers is planning to invest in the production of wind energy. In this complicated situation the issues at stake reach from environmental and ecological concerns, safety, profitability, financial and technical feasibility, reliability of the electricity supply, spatial planning and maybe more. At the same time these issues are under (shared) control of numerous actors. For examples, the farmer's organization might be willing to sell the land for the power plant if they are granted licenses for the construction of wind turbines and receive the right to connect to the electricity network and a good price for the electricity produced. At the same time the water authority opts for air-cooling instead of water-cooling with reference to ecological concerns, down stream water users and climate change, while spatial planning and local environmental groups are of the opinion that the industrial image of cooling towers does not fit the mainly rural setting.

According to Coleman such a complex decision making process can be described in term of exchange of control. The actors involved need to interact and negotiate to establish the distributions of control and interest and consequently the value of control over the issues at stake to come to a decision (Coleman 1990; Timmermans 2004). At the same time an alternative design for the power plant needs to be developed that incorporates the issues at stake in such a way that the exchange of control can be operationalized through the implementation of this alternative (Timmermans 2004).

The Linear System of Action (LSA) is the formal implementation of this theory and is based on micro-economic theory and its use of utility theory (Coleman 1990), but deviates from micro-economic theory in its prescription of a specific form of the utility function. Micro-economic theory takes a more general approach and proves 
Table 2 Matrices of control $C$ and interest $X$ specifying the LSA

\begin{tabular}{|c|c|c|c|c|c|c|c|c|c|c|c|}
\hline & & $C$ & & & & & & $X$ & & & \\
\hline$C_{11}$ & $C_{1 j}$ & $C_{1(j+1)}$ & $\ldots$ & $\ldots$ & $C_{1 n}$ & {$\left[X_{11}\right.$} & $X_{1 i}$ & $X_{1(i+1)}$ & $\ldots$ & $\ldots$ & $X_{1 m}$ \\
\hline$C_{i 1}$ & $C_{i j}$ & $C_{1(j+1)}$ & $\ldots$ & $\ldots$ & $C_{i n}$ & $X_{j 1}$ & $X_{j i}$ & $C_{1(j+1)}$ & $\ldots$ & $\ldots$ & $X_{j m}$ \\
\hline$C_{(i+1) 1}$ & $\ldots$ & $C_{(i+1)(j+1)}$ & $\ldots$ & $\ldots$ & $C_{(i+1) n}$ & $X_{(j+1) 1}$ & $\ldots$ & $X_{(j+1)(i+1)}$ & $\ldots$ & $\ldots$ & $X_{(j+1) m}$ \\
\hline$\cdots$ & $\cdots$ & $\cdots$ & $\cdots$ & $\cdots$ & $\cdots$ & $\ldots$ & $\ldots$ & $\ldots$ & $\ldots$ & $\cdots$ & $\ldots$ \\
\hline$\ldots$ & $\ldots$ & $\cdots$ & $\ldots$ & $\ldots$ & $\ldots$ & $\ldots$ & $\ldots$ & $\ldots$ & $\ldots$ & $\ldots$ & $\ldots$ \\
\hline$C_{m 1}$ & $C_{m j}$ & $C_{m(j+1)}$ & $\ldots$ & $\ldots$ & $C_{m n}$ & $\left\lfloor X_{n 1}\right.$ & $X_{n i}$ & $X_{n(i+1)}$ & $\ldots$ & $\ldots$ & $X_{m n}$ \\
\hline
\end{tabular}

that under conditions of positive and declining marginal utility equilibrium exists. ${ }^{2}$ In addition, Coleman fixes the general shape of the utility function in the LSA which makes it possible to calculate the competitive equilibrium. The LSA uses a multiplicative utility function:

$$
U_{i}=c_{i 1}^{x_{1 i}} \cdot c_{i 2}^{x_{2 i}} \ldots \cdot c_{i m}^{x_{m i}},
$$

where $U_{i}$ is the total utility of actor $i, c_{i j}$ is the amount of control over issue $j$ held by actor $i$ and where $x_{j i}$, the interest of actor $i$ in issue $j$, expresses the contribution that this control makes towards the utility of actor $i{ }^{3}$ The variables of the utility function correspond directly to the basic concepts of the LSA: control over issues, $c_{i j}$, and interest in issues, $x_{j i}$. Furthermore in the LSA control and interest are relative notions and scaled arbitrarily to 1 . In matrix notation a LSA for a social system of $n$ actors and $\mathrm{m}$ issues is fully specified by the matrices $X$ and $C$, the distributions of control and interest over the actors and the issues (Table 2).

For a large number of actors and a large number of issues the conditions for a fully competitive market are realized and exchanges of control converge on a unique competitive equilibrium in which each issue has a single price, the rate at which it is traded in all transactions. At equilibrium all actors have maximized their control over the issues that most interest them subject to their initial control and no further exchanges of control occur. A method to calculate the competitive equilibrium for such a linear system is presented in the Appendix.

\section{A non-linear system of action}

The LSA presented above is an equilibrium model. In the LSA there are no changes in the equilibrium values of issues neither of the distribution of control over actors; the matrices $C$ and $X$ are fixed. Societal transitions however exactly involve such

\footnotetext{
${ }^{2}$ Micro economic theory does not specify the shape of the utility function. Given the conditions on the first and second derivative of the utility function, positive contribution to utility and declining marginal utility, micro-economic theory proves the general existence of equilibrium, as described in a famous paper by John Nash (1950).

${ }^{3}$ This multiplicative form is also known as a Cobb-Douglas production function and relates production to the input of capital and labour. The utility function used by Coleman in the LSA has the same shape as the Cobb-Douglas production function and control in the LSA is similar to capital while interest reflects labour.
} 
shifts from one dynamic equilibrium to another. According to Coleman three sources of a shift in equilibrium exist (Coleman 1990). First, issues can enter or leave the system, second, new actors can enter the system, and third actors and issues can enter or leave the social system simultaneously (Coleman 1990: pp. 895-896). All three developments result in a shift in the distribution of interest and control of the LSA and consequently a new equilibrium. Coleman does elaborate on the reasons for actors or issues to enter or leave the system for the specific case of single- and double-contingency panics (Coleman 1990: pp. 899-931) but does not present a more general explanation.

To describe the social dynamics involved in transitions a more general explanatory theory of equilibrium shifts in the LSA is required. In the following we propose a variation and selection procedure of actors, based on a rational approach at both the actor and the system level. For individual actors in the social system it is rational to select actors into the social system that increase their own opportunities for exchange of control and thus realizations of their individual interests. At the system level this rational behavior of individual actors leads to a collective outcome in which actors adding most to the opportunities for profitable exchanges of control for the entire system are retained.

Whether we define this mechanism as a pure selection mechanism operating on existing actors outside the social system studied, as proposed by Coleman (1990) or as a mutation procedure which forces less fit actors to mutate in order to continue to be a member of the specific social system is not relevant for the dynamics of the model proposed. We favor the mutation explanation because it links to the idea that an important difference between the social dynamics in equilibrium conditions and in transitions is the shift in equilibrium of the LSA caused by changing interests or control of actors under transition conditions. This change in interest or control of an actor can be interpreted as a contribution to the change in the deep structure of the social system (Gersick 1991) or a mechanism to self-organize into a critical state (Bak et al. 1988) and can be explained in terms of the three phases, frame breaking (unfreezing), frame moving and frame re-alignment (re-freezing) of Lewin's process for changing social values (Lewin 1951). This model is also extensively applied in change management and leadership theories (Worren et al. 1999; Fiol et al. 1999).

The interpretation of mutations through the change of individual values is further bolstered by the observation of two prominent authors on rational choice theories, Michael Hechter $(1987,1988)$ and again James S. Coleman in their theories of group solidarity. These theories explain the emergence of groups from the rational selfinterested behavior of individual actors. Coleman's line of thinking develops around the need for actors to interact in order to produce joined goods contributing to the realization of the interests of the individual actor (Coleman 1986). Changes in the distribution of the control of an individual actor can similarly be attributed to changes in the perception of the remaining actors in the system on the control of the mutated actor, as the concept of control is radically subjective (Sebenius 1992). Next we develop the computational implementation of the variation and selection procedure proposed.

Selecting the actor offering the least possibilities for profitable exchanges of control needs an evaluation at the system level. The dependence of an actor is a quantitative measure of the contribution of the respective actors to the total potential for 
profitable exchanges of control in that LSA. When the matrices $C$ and $X$ of the LSA are known the matrix of inter-actor dependencies, $D_{a c t}$, can be calculated as:

$$
D_{a c t}=C \times X
$$

$D_{a c t}$ is a square matrix of size $m \times m$ and its entries $d_{i j}$ give the dependence of the column actor, $i$, on the row actor, $j$. Dependence is calculated as the sum of the control of the 'independent' row actor in $C$ times the interest of the 'dependent' column actor in $X$. The main diagonal of matrix $D_{\text {act }}$ gives the self-dependency of actors (Timmermans 2004). Self-dependency of actors indicates to which extend actors are independent of the other actors in realizing their interests. It follows logically that the most self-dependent actor is also the most independent actor in the social system and consequently offers the minimum contribution in terms of potential exchange of control. This actor is selected for mutation.

In terms of the LSA mutating an actor means that the interest and control of the actor are changed. For an individual actor mutation is a purposive action, involving unfreezing and re-freezing (Lewin 1951), with the aim to save his/her membership of the social system and thus his/her opportunities to produce joined goods contributing to his/her individual interests (Coleman 1986). To satisfy the requirements of the social system as a whole the mutation of the actor should take place at the issue that contributes least to the potential for exchanges of control. In analogy with the selection of the mutating actor, the issue at which the actors' distribution of interest and control are changed can be selected by determining the least dependent issue of the LSA. When the matrices $C$ and $X$ of the LSA are known the matrix of inter-issue dependencies, $D_{\text {iss }}$, can be calculated as:

$$
D_{i s s}=X \times C
$$

$D_{i s s}$ is a square matrix of size $n \times n$ and the entries $d_{i j}$ in the matrix give the dependence of the row issue $i$, on the column issue, $j$. Dependence is calculated as the sum of the interest in the 'dependent' row issue in $X$, times the control over the 'independent' column issue in $C$. Dependence of issues indicates to which extend exchanges of control involving the 'independent' column issue are required to further decision-making on the 'dependent' row issue. The main diagonal of matrix $D_{\text {iss }}$ again gives the self-dependency, this time of the issues (Timmermans 2004). The self-dependency of an issue indicates to which extend decision making on this issue involves other issues. It follows logically that the most self-dependent issue is also the most independent issue in the social system and consequently offers the minimum contribution in terms of potential exchange of control.

In line with the rationale developed above, a random procedure for the mutation of an actor in the LSA is specified. In this procedure the interest and control of the most self-dependent actor, $k$, for the most self-dependent issue, $l$ (cell $k l$ in $C$ and cell $l k$ in $X$, see Table 2) are replaced by a random number in the range $C_{i=k, j}^{\min }$ to $C_{i=k, j}^{\max }$ and $X_{j=l, i}^{\min }$ to $X_{j=l, k}^{\max }$, while keeping total control of the mutated actor and total interest in the mutated issue unchanged through normalizing the vectors to their original lengths. This procedure both conserves the total power of the selected actor 
and total interest in the selected issue and avoids sudden changes in the distribution of power and interest in the social system.

This concludes the theoretical development of a dynamic model of a social system consisting of rational actors characterized by control over and interest in issues. The dynamics are driven by a variation and selection procedure. The typical dynamics of such a model in the absence of exchange is shown in the first 50.000 simulation steps of Fig. 1. In this figure the simulation results of the Non-linear System of Action (NLSA) are characterized using distance from equilibrium, indicating the amount of exchange of control required to reach equilibrium from the current state of the model. Distance from equilibrium, ${ }^{s} c^{\phi}$, at iteration step $s$ is calculated as:

$$
{ }^{s} c^{\phi}=\sum_{i j}\left|{ }^{s} c_{i j}^{*}-{ }^{s} c_{i j}\right|,
$$

where ${ }^{s} c_{i j}$ is the actual control of decision maker $i$ over issue $j,{ }^{s} c_{i j}^{*}$ is the equilibrium control of actor $i$ over issue $j$ and $s$ is the number of the iteration step. See the Appendix for a procedure to calculate the distribution of equilibrium control, ${ }^{s} c_{i j}^{*}$.

In the first part of the simulation run the model moves away from equilibrium because mutated actors adding to the potential for exchange of control are retained in the social system. After this initial period, the model reaches a dynamic equilibrium, a state where new actors are not able to push the social system further out of equilibrium and where unfavorable mutations cause the system to make minor moves back to equilibrium. After 50.000 steps the mutation procedure is stopped and an exchange module is started causing the social system to fall back to equilibrium in the next 50.000 steps. The exchange process randomly selects two actors and two issues and implements the exchange when profitable to both actors.

The exchange procedure implemented in the simulation of Fig. 1 is a random procedure. For the NLSA we need a procedure that simulates social development through actual exchanges of control. Exchange of control in a real world social system requires two conditions to be fulfilled. First, exchange of control can

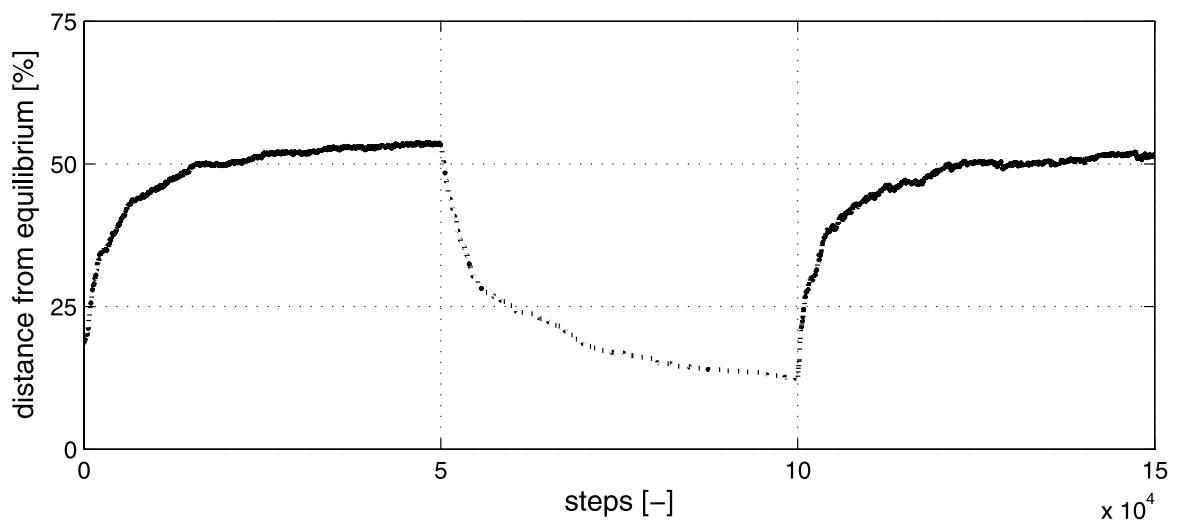

Fig. 1 Distance from equilibrium step 1-50.000 mutate only, step 50.000-100.000 exchange only, step 100.000-150.000 mutate and exchange 
only take place if a 'double coincidence of wants' exists between the actors involved. The 'double coincidence of wants' means that an actor wants something from another actor and that this other actor has something to offer in return. In the (N)LSA, if actor $i$ wants more control over issue $j$ and less control over issue $k$ while actor $l$ wants more control over issue $k$ and less control over issue $i$ they can engage in a bilateral exchange of control over issue $i$ for control over issue $j$. Second, the exchange can only be implements if a solution, alternative or decision exists in practice that mobilizes the exchange (Timmermans 2004; Crozier and Friedberg 1980).

For example, if a potential for exchange of control exists between agricultural landowners and a water authority regarding the use of their land for controlled flooding, this exchange cannot be implemented without infrastructure that keeps the flooding controlled and the farm buildings save and accessible. If this infrastructure is not feasible, the exchange cannot be implemented. Both the identification of profitable exchanges of control, establishing the value of control over the different issues and the development of feasible solution are interactive processes, in which interdependent actors engage in negotiations in order to realize their interests by creating collective goods (Timmermans 2004; Coleman 1990; Crozier and Friedberg 1980).

We now develop the exchange module along the following line of thinking. First, we suppose that actors primarily engage in negotiation concerning exchanges of control with actors on which they depend in reaching their goals and that the identification of potential exchanges of control, including the setting of the prices for control over specific issues, mostly result from these type of negotiations. Second we assume that concrete alternatives that allow for the implementation of these exchanges of control mostly result from interaction on inter-dependent issues. This means that we can again use the matrices $D_{a c t}$ and $D_{\text {iss }}$ to select the two most dependent actors and two most dependent issues and implement the exchange of control accordingly. For the value of control over the different issues equilibrium prices are used, calculated in accordance with the procedure described in the Appendix. The third part of Fig. 1, step 100.000 to 150.000 shows the typical dynamics of the NLSA. Again first the model is pushed away from equilibrium. In this phase, the potential for exchange of control added by mutated actors outperforms the pressure to move back to equilibrium caused by the exchanges implemented. After some time these two processes reach a dynamic equilibrium, a poised state where the model is kept at a certain distance from equilibrium. In the next section we present some simulation results of the model in relation to the specific dynamics of transitions.

\section{Transition characteristics of the non-linear system of action}

The NLSA described above is developed to model transitional behavior of social systems. In order to do so, simulation results should show dynamic behavior typical for the punctuated equilibrium paradigm. In this section we evaluate the dynamics of the NLSA model regarding two characteristics pertinent to societal transitions. First we look at the occurrence of power law distributions in the simulation record of exchanges of control and address the related punctuated equilibrium behavior. Second we look into structural change or transitions. For the analysis we use results 
from model simulations for different sizes of the NLSA. All simulations are made using randomly generated LSA's with 2 up to 45 actors and issues. The matrices $C$ and $X$ are generated by random permutation of vectors of the appropriate size and normalizing the resulting matrices column wise. This procedure resembles the ability of human actors to derive their preferences up to a strong preference order through paired comparisons (Beroggi 1999, 2000). All simulations concerning the occurrence of power law distributions are continued for 250.000 steps after a burn in period of also 250.000 steps. The results used to analyze structural change are drawn from a randomly created NLSA of 17 actors and 29 issues. These runs are continued for 100.000 steps after a burn in period of 50.000 steps.

\subsection{Power law distribution and punctuated equilibrium}

Rotmans, Kemp and Van der Brugge state that transitions show episodic development (Rotmans 2005; Rotmans et al. 2001; Van der Brugge et al. 2005; Kemp et al. 1998). Similar accounts of social development as an alternation of long periods of stability and short periods of change can be found in the agenda setting literature (Kingdon 1984; Jones and Baumgartner 2005; Baumgarter and Jones 1993), the literature on population dynamics and economic development (Davis 1945; Schumpeter 1934), psychology, group dynamics, organization science, biology and self-organizing systems (Gersick 1991) and evolutionary theory (Gould and Eldredge 1977; Eldredge and Gould 1972). In a theoretical analysis of this episodic behavior, Bak and Sneppen relate punctuated equilibrium behavior to self organized criticality (SOC) and scale-free behavior as signified by a power law distribution of the output of a critical system (Bak and Sneppen 1993).

The concept of power laws is related to the idea that small events happen all the time and big events happen less frequently. In the NLSA the relevant event is the exchange of control. According to Coleman exchange of control is the driving force and measure of social development (Coleman 1990). Big and frequent exchanges of control signify periods of fast social development like societal transitions while periods of rare and small exchanges or the absence of exchanges of control characterize periods of slow development and stagnation.

To investigate the frequency distribution of the exchanges of control in the NLSA, a total of 61 simulations with randomly generated NLSA of different sizes where run. The size of the NLSA models in term of actors and issues where chosen to cover the range of 2 to 45 actors and 2 to 45 issues, while combining both small numbers of actors with large number of issues as large number of actors with small number of issues. For the analysis the models are characterized by their size, where size equals the number of actor's times the number of issues. For all models frequency distributions of the magnitude of the exchanges of control observed in the simulations are drawn up. A typical frequency distribution is presented in Fig. 2, both as bar graph and on a log-log plot. The goodness of fit of the straight line in Fig. $2 b$ is indicative for the conformity of the frequency distribution of exchanges of control to a power law. The slope of the line on the log-log plot equals the exponent $b$ of the power function, $a x^{b}$, fitted through these points, while the adjusted R-square reflects the goodness of fit. In the subsequent section adjusted R-squares are used to evaluate the dynamics of the NLSA. 


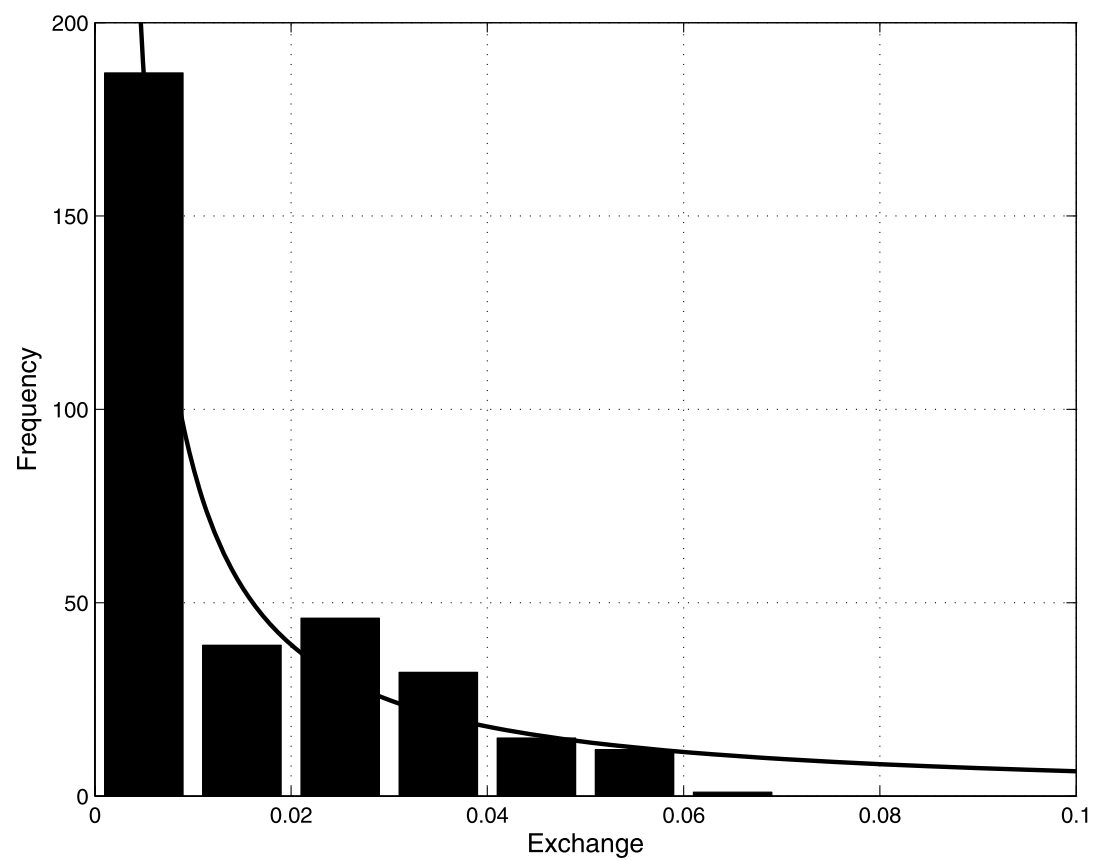

(a)

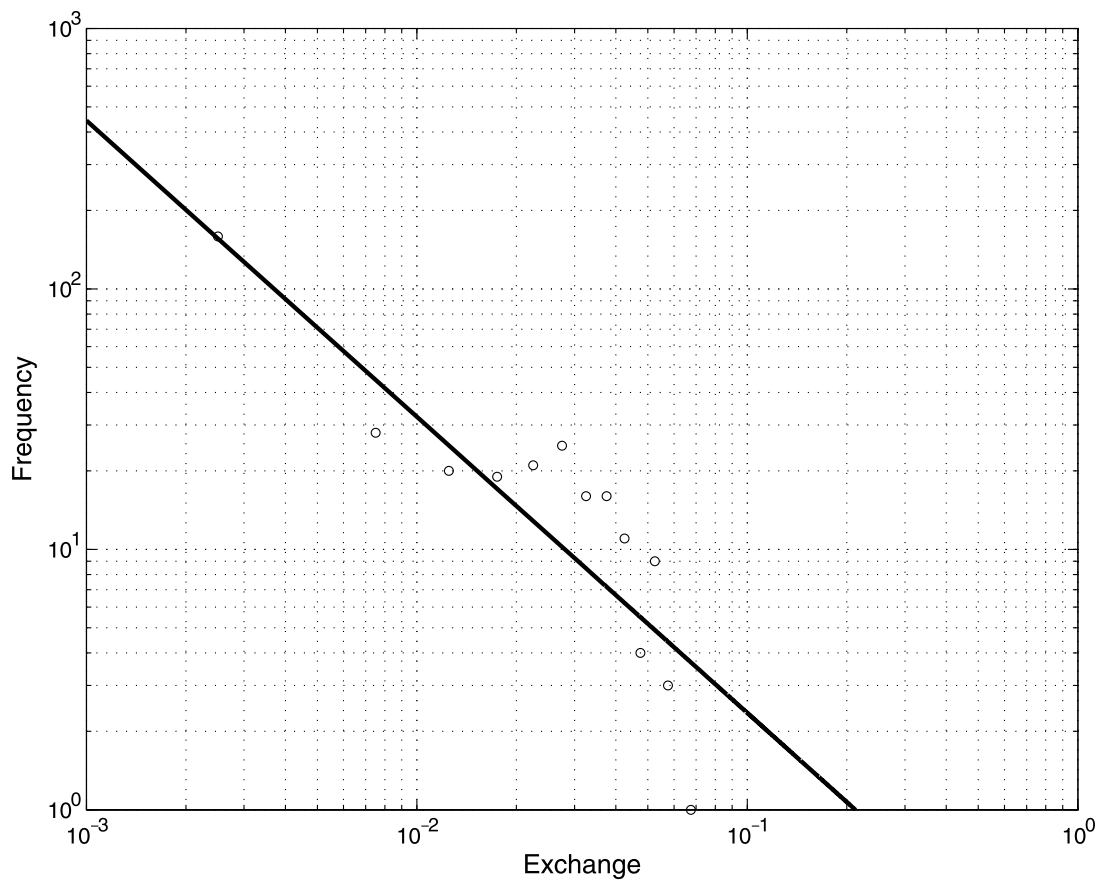

(b)

Fig. 2 Characteristic frequency distribution of exchanges of control. (a) Bar graph, (b) Log-log plot 
To evaluate the occurrence of power laws in the frequency distribution of the exchanges of control for a wide range of models, a power function is fitted through all 61 distributions obtained in the simulations. In Fig. 3a the adjusted R-squares of the fitted power functions are plotted on the vertical axis against the size of the NLSA on the horizontal axis. From Fig. 3a it appears that if the size of the NLSA exceeds 99 , the adjusted R-squares exceed 0.94 , identifying a good fit of the power function. These data proof the occurrence of power law distributions in the frequency distributions of the exchanges of control in NLSA simulations for models with a size exceeding 99.

In Fig. 3b, the exponents of the power function obtained are plotted against the size of the respective models. Here a reasonable relation between size and exponent of the power function appears. For models of limited size the exponent approaches zero. The power function than reduces to a line with a constant value, which means that for small NLSA the exchanges are distributed around some average value. For NLSA with a bigger size the exponents obtain values of -1.5 to -2.0 , which is in the same order as Bak and Sneppen obtained in their simple model of evolution (Bak and Sneppen 1993).

For punctuated equilibrium dynamics, besides the power law distribution of the magnitude of the model output, the distance in time between exchange events is of interest (Jensen 1998). We expect a power law distribution of these distances in steps. Figure 4 shows the results of this analysis for the same simulation used for Fig. 3 . Figure 4a presents the adjusted R-squares for a power law fitted through the distance between events for model sizes ranging from 4 to 2025. The results are similar to the results of Fig. 3a. Adjusted R-squares, however, are somewhat lower and the two lines intersect at adjusted R-squares of 0.84 and a size of 87 . The exponents of the power law range from -0.5 to -1.2 and are smaller than the coefficients found in Fig. 3b.

The analyses above proves that NLSA with a size, number of actors times number of issues, exceeding 100, self-organize into a critical state and show punctuated equilibrium dynamics in which periods of limited exchange of control and periods of high exchange of control alternate with periods without exchange. Rotmans et al. connect this alternation of periods of slow and fast social development with the concept of social transitions (Rotmans 2005; Rotmans et al. 2001; Van der Brugge et al. 2005; Kemp et al. 1998). Although Rotmans et al. do not explicitly use the terminology of Bak and Sneppen, Gould and Eldredge and Gersick, their description of transitions and references to the literature on complex adaptive systems mirrors the theories developed by these authors.

Next we look into the dynamics of the NLSA in more detail and investigate the punctuated-equilibrium dynamics directly. We compare a small NLSA of 3 actors and 3 issues and thus a size of 9 and a bigger NLSA of 17 actors and 29 issues and a size 493. The second model lies well into the areas of Figs. 3a and $4 \mathrm{a}$ where power law distribution of the NLSA output occurs and punctuated equilibrium dynamics can be expected. In the smaller model, according to Fig. 3a, a distribution of exchanges of control around an average is expected while long periods of quiescence will be absent.

The output for the smaller and bigger NLSA is plotted in Figs. 5a and 5b respectively together with the cumulative exchange of control for the entire simulation pe- 


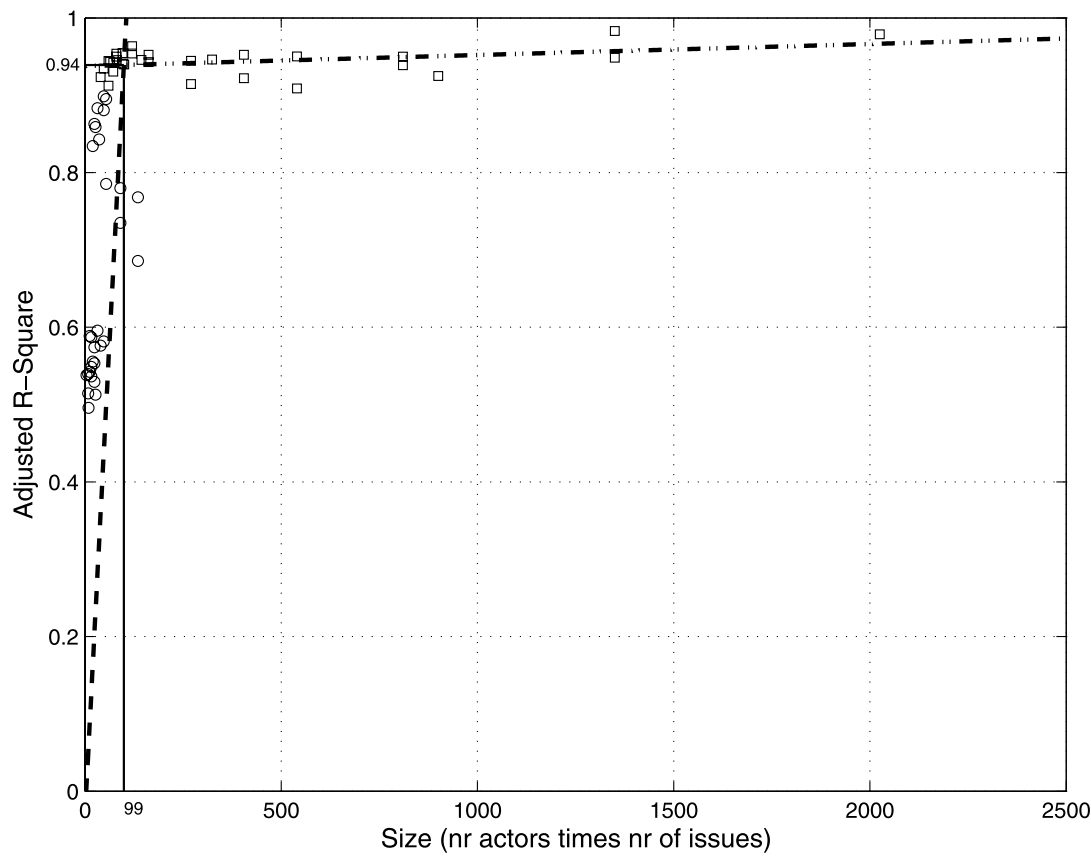

(a)

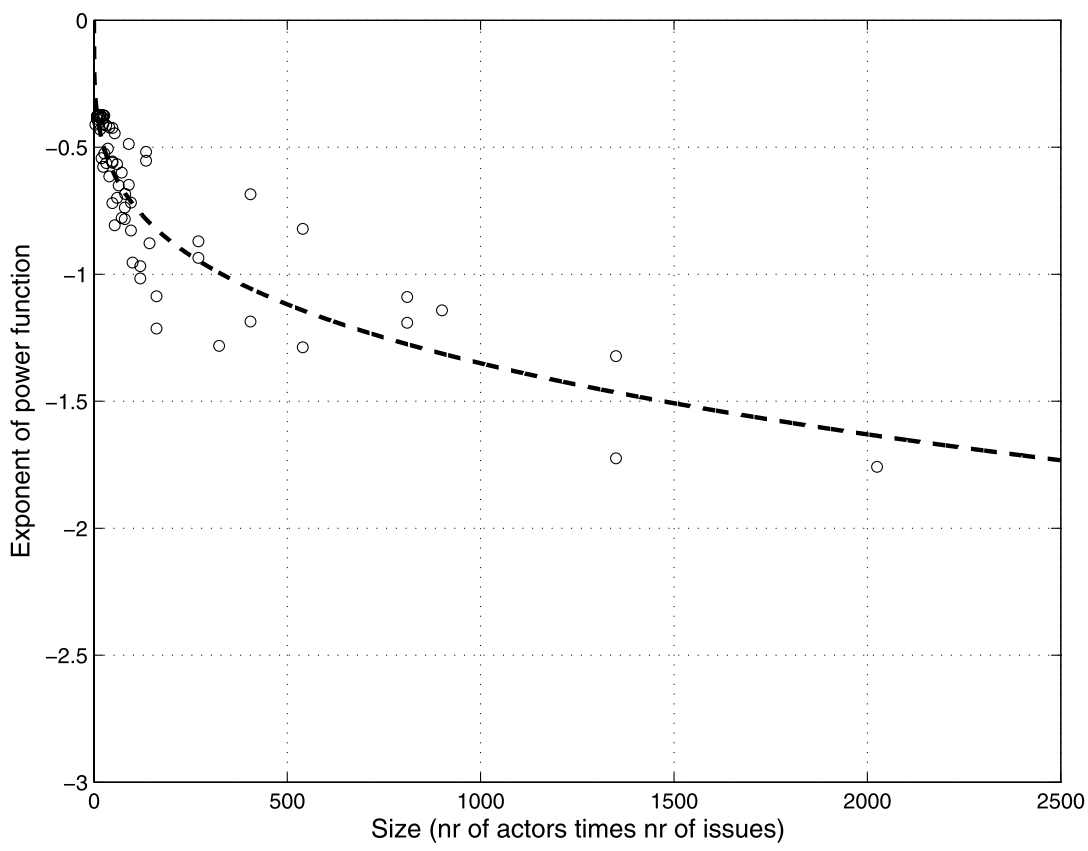

(b)

Fig. 3 Power law distribution of the frequency distribution of exchanges. (a) Goodness of fit to the power function $f(x)=a x^{b}$. (b) Exponents $b$ of the power function $f(x)=a x^{b}$ 


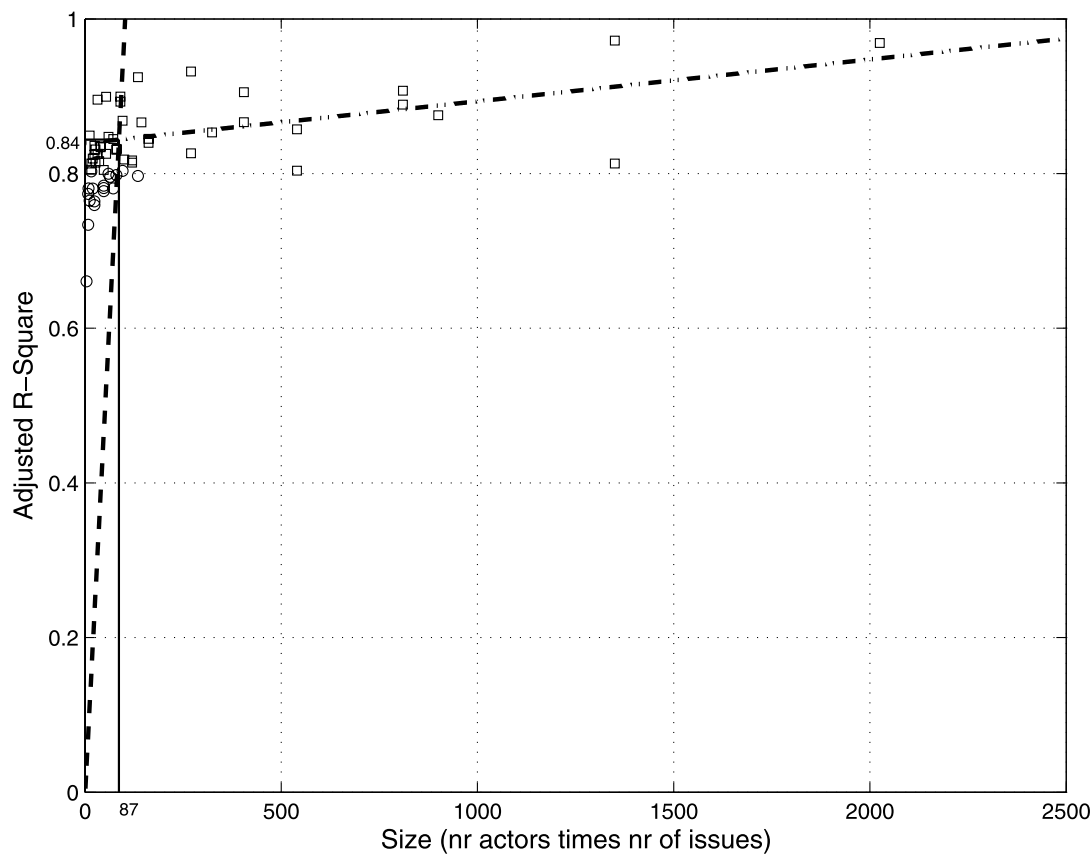

(a)

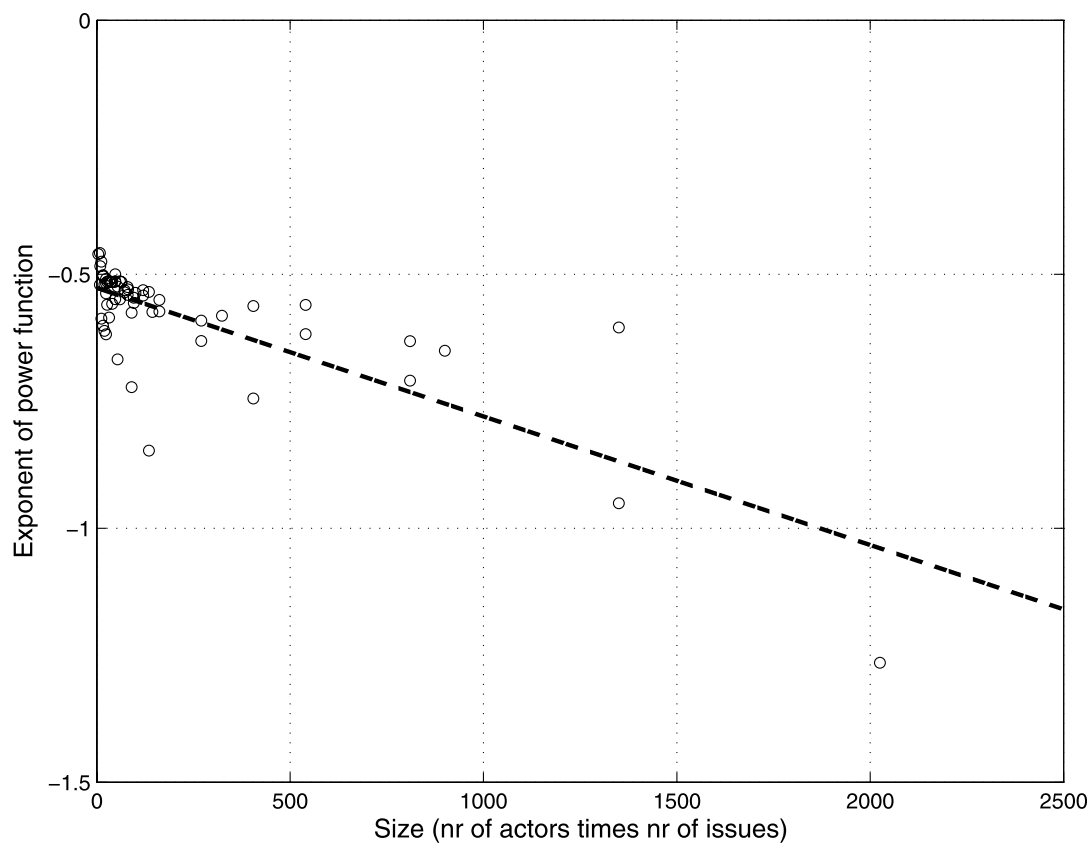

(b)

Fig. 4 Power law distribution of the distance between exchanges. (a) Goodness of fit to the power function $f(x)=a x^{b}$. (b) Exponents $b$ of the power function $f(x)=a x^{b}$ 
riod. For the small model no punctuated equilibrium behavior is present in the record and exchanges of control are distributed around an average. As a result the speed of social development reflected by cumulative exchange is constant and cumulative exchange grows in a straight line. In Fig. 5b, the big NLSA, punctuated equilibrium behavior shows up clearly in the record of exchanges of control and an alternation of slow or no social change and fast social change is observed in the development of cumulative exchange represented by the dotted line. The scales of the two plots cannot be compared as the numerical values are related to the size of the model.

\subsection{Structural change or transition}

A second concept central to societal transition is structural change (Rotmans 2005; Rotmans et al. 2001; Van der Brugge et al. 2005; Kemp et al. 1998). In the body of literature on societal transitions, this structural change is cast in terms of large scale technological, economical, ecological, socio-cultural and institutional change (Rotmans et al. 2001) in which a dominant structure or design of a social system, the regime, is replaced by a social system with a different structure and design, the niche (Rotmans et al. 2001; Geels and Kemp 2000). This dominant structure or design is similar to what Gersick describes as deep structure (Gersick 1991).

In transition theory the regime is both characterized by a 'dominant' set of actors and a 'dominant' set of substantive characteristics, like institutions, practices, structures and artifacts or infrastructures (Rotmans 2005; Van der Brugge et al. 2005; Kemp et al. 1998). At an abstract level, these regime characteristics translate into a distribution of power of actors and value of issues in the NLSA. Power of actors is a straightforward concept, both from definition of regimes in transition theory as from the NLSA. The translation of the substantive characteristics of the regime into values of issues is however less clear-cut and will be explained below. In the NLSA all issues obtain a value based on the interest of actors in the respective issues. If we characterize the substantive elements of a regime with issues and rate the level up to which these issues are served by the current regime with the values, the NLSA gives us a quantitative characterization of the issues by the regime. For example, if in the case of decision-making on the construction of a power-plant profitability is one of the issues, a high value for control over profitability indicates that the current regime highly values this issue when taking decisions, while in a similar case where actors representing environmental concerns are member of the regime, issue of sustainability will have a higher value. For a method to define these issues for a real world social system we refer to Timmermans, Schouten et al. and Timmermans and Beroggi (Timmermans 2004; Schouten et al. 2001; Timmermans and Beroggi 2000).

Structural change can thus be described in terms of a significant change in the power structure and/or value structure of the NLSA. The distribution of power and values are both system level entities and are expressed in the power vector, $r$, and the value vector, $v$ of the LSA. These vectors give the power of each actor $i$ and the value of each issue $j$ and are vectors of length $m$ and $n$ respectively. Both vectors can be derived directly from the matrices $C$ and $X$ (see Appendix). For the analysis in this article we define a structural change of the power and/or value structure as a persistent change in the most powerful actor and the most valued issue. Persistence is 


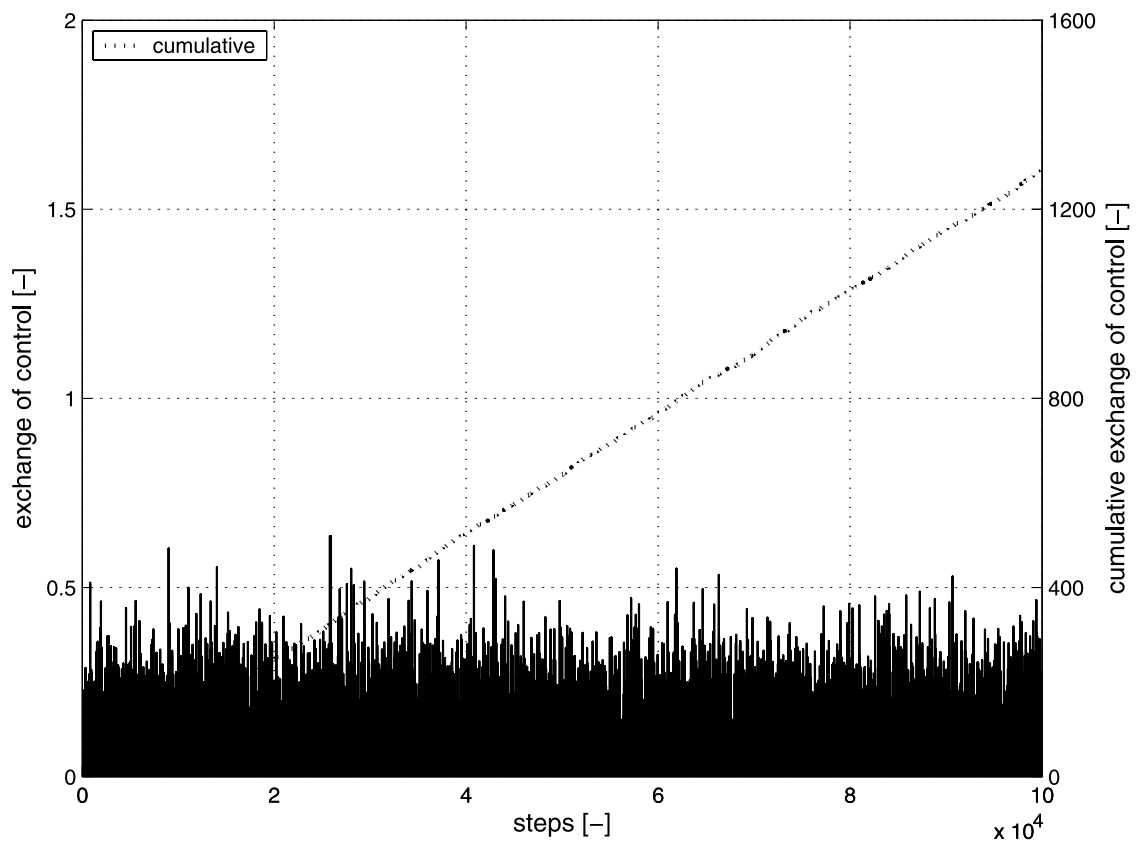

(a)

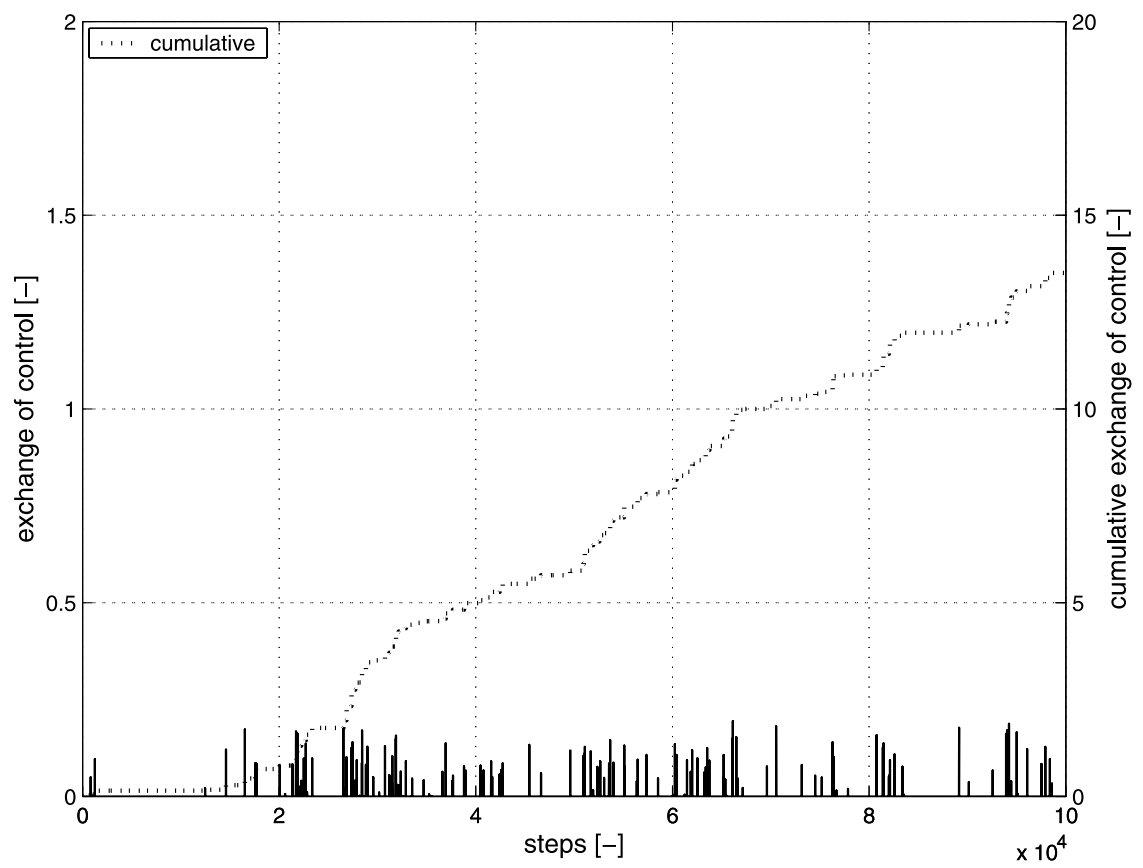

(b)

Fig. 5 Punctuated equilibrium dynamics in the NLSA. (a) NLSA with 3 actors and 3 issues (small). (b) NLSA with 17 actors and 29 issues (big) 
determined by a threshold in steps. We identify this structural change with a transition or regime change as defined by Rotmans et al. (Rotmans 2005; Van der Brugge et al. 2005; Geels and Kemp 2000; Kemp et al. 1998).

In Fig. 6 the occurrences of structural change in the power structure and the value structure of the NLSA with a threshold of 500 steps are presented. Each time the power or value structure changes and remains in place for at least 500 steps, a vertical line marking structural change, regime change or transition is plotted. The figure uses the same simulation as used in Fig. 5b. In case a threshold smaller than 500 is used, far more regime changes occur, however, long periods of stable regimes remain. Most of the regime changes seem to occur in the vicinity of periods of rapid change. Unstable periods where change and stagnation alternate often show a few regime changes in a limited period. These are the periods of transition, where a 'struggle' takes place between the actors to take over the regime. Only after some time a new stable regime emerges.

To confirm the relation between exchange events and regime changes in both terms of power and values, the empirical distribution functions of the distance in steps from a transition in the power regime to an exchange event $f\left({ }^{\operatorname{tran}} P\right)$ and the distance in steps from a transition in the value regime to an exchange event $f\left({ }^{\operatorname{tran}} V\right)$, the empirical distribution of the distance for any step to a change in power regime $f\left({ }^{\text {step } P}\right)$ and the distance for any step to a change in the value regime $f\left({ }^{\text {step }} V\right)$ are derived and compared using a single tailed two-sample KolmogorovSmirnov test. The distributions are derived and tested both for the backward distance and the forward distance between regime changes and exchange events [ $\left.f\left({ }^{\text {tran }} P_{\text {back }}\right), f\left({ }^{\text {tran }} P_{\text {forward }}\right), f\left({ }^{\text {tran }} V_{\text {back }}\right), f\left({ }^{\text {tran }} V_{\text {for }}\right)\right]$ and backward and forward distance for all steps [ $\left.\left.f\left({ }^{\text {step }} P_{\text {back }}\right), f\left({ }^{\text {step }} P_{\text {forward }}\right), f\left({ }^{\text {step }} V_{\text {back }}\right), V^{\text {step }} V_{\text {forward }}\right)\right]$. The null hypothesis for the single tailed test is that respectively $f\left({ }^{\operatorname{tran}} P_{\text {back }}\right)$, $f\left({ }^{\text {tran }} P_{\text {forward }}, f\left({ }^{\text {tran }} V_{\text {back }}\right)\right.$ and $f\left({ }^{\text {tran }} V_{\text {forward }}\right)$ have the same continuous distribution as respectively $f$ ( $\left.{ }^{\text {step }} P_{\text {back }}\right), f\left({ }^{\text {step }} P_{\text {forward }}\right), f$ ( $\left.{ }^{\text {step }} V_{\text {back }}\right)$ and $f$ ( $\left.{ }^{\text {step }} V_{\text {forward }}\right)$, while the alternative hypothesis is that the dataset labeled 'tran' are smaller than datasets labeled 'step', indicating that regime changes occur significantly closer to exchange events. At the 0.05 significance level, only the alternative hypotheses for $f\left({ }^{\operatorname{tran}} P_{\text {back }}\right)$ is accepted $(\alpha=0.024)$, indicating that transitions in the power regime normally occur close after an exchange event. The alternative hypothesis for, $f\left({ }^{\operatorname{tra}} P_{\text {forward }}\right)$ is not accepted $(\alpha=0.069)$. The alternative hypothesis for $f\left({ }^{\operatorname{tran}} V_{\text {back }}\right)(\alpha=0.206)$ and $f\left({ }^{\text {tran }} V^{\text {forward }}\right)(\alpha=0.649)$ are both rejected. We conclude that changes in the distribution of power in the NLSA normally happen close after an exchange event, while also quit often exchanges occur after a change in power structure. No relation exists between changes in the value structure of the NLSA and exchange events.

From the characteristics of the NLSA, punctuated equilibrium dynamics, power law distribution for both magnitude of exchanges of control and distance in time steps between exchanges of control, alternation of periods of stagnation and periods of accelerated change, structural changes in the distribution of power over the actor and value over the issues, combined with a strong relation between exchange events and changes in the power distribution, we conclude that the NLSA performs well in modeling the specific characteristics of societal transitions as hypothesized by tran- 


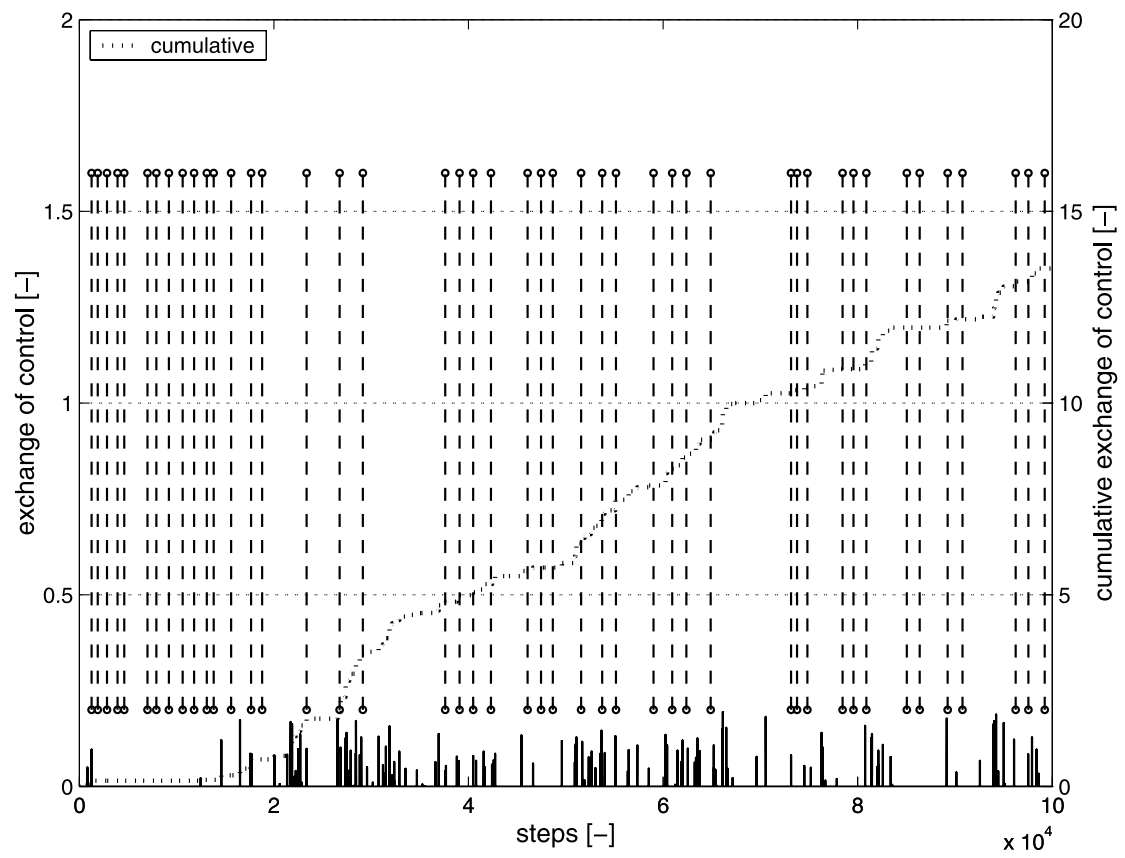

(a)

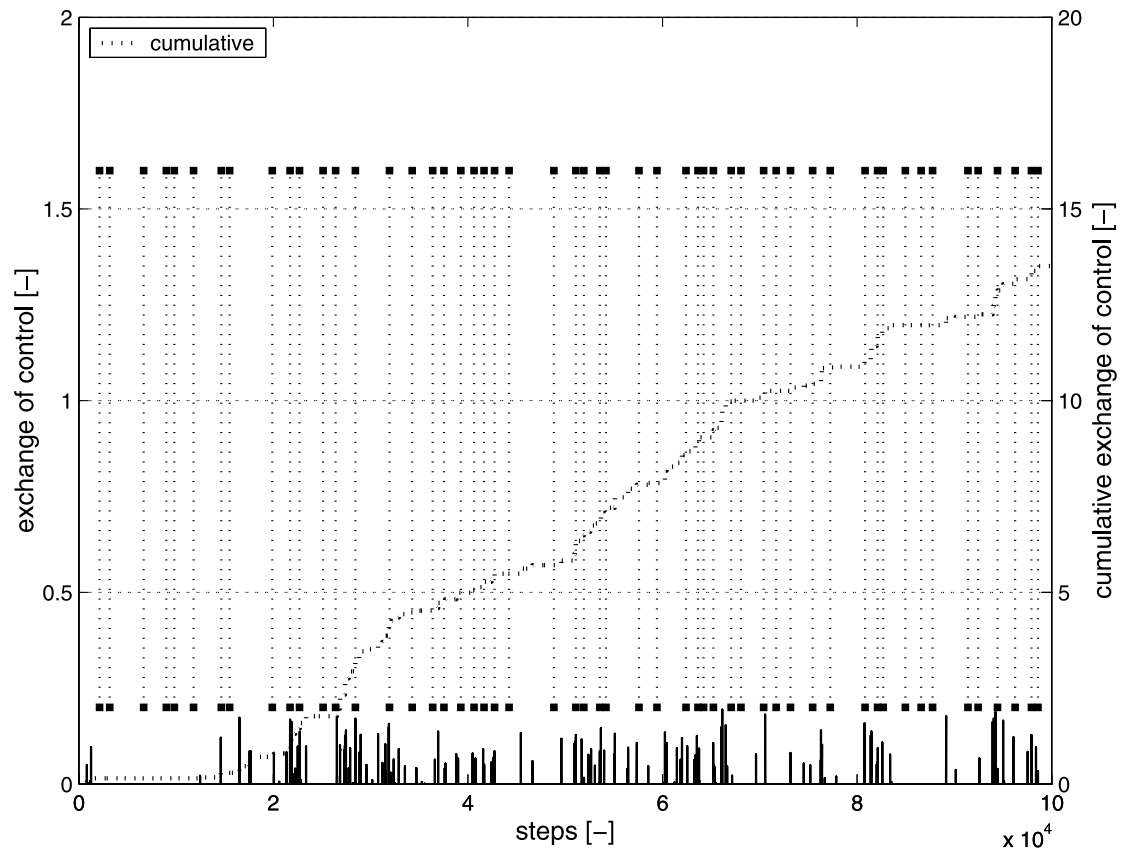

(b)

Fig. 6 Structural Changes in the NLSA. (a) Structural change in the distribution of power. (b) Structural change in the distribution of values 
sition theory. At the same time the model has a potentially strong connection with practice and is well embedded in sociological theory.

\section{Possible application and further research}

The NLSA can be used to study societal change and social transitions in different modes. First, the model can be used as a simulation tool generating its own social development, characterized by the speed of development, the direction of the development in terms of the issues, occurrence of changes in the distribution of power of actors or values of issues. In this case the model operates internally without a connection to an outside world or is treated as a model of an entire society. The results and insight gained from this type of studies primarily help us to better understand the dynamics of a social system and increase our insight in the conditions under which transitions occur. In the previous section some results of this type of research were presented in relation to the occurrences of transitions.

In this more theoretical analytic realm also the analysis of network characteristics generated by the NLSA is of interest. This type of analyses would include the analysis of network characteristics from social network analysis like centrality, density and cores and cliques (Scott 2000) in relation to speed and direction of change and transitions. This type of research promises to yield relevant observations for transition management, as findings on network characteristics can be translated to the management of real world social networks. Transition management then takes the shape of network management, with the aim to develop network structures that are positively related to radical change.

Some authors have related empirical data on social networks to scale free networks showing power law distribution of their degree (Whitmeyer and Yeingst 2006). Others have found power law distributions of network components and claim that these networks are self-organized (Bak 1996; Dorogovtsev et al. 2003; Jensen 1998) resulting in globally stable and locally instable social networks (Whitmeyer and Yeingst 2006). Whitmeyer and Yeingst also hypothesize that self-organized critical networks are robust and resilient and therefore difficult to change. At this point in time the relation between evolving networks and network topology (Watts 2002; Albert and Barabási 2002) and societal transitions are unclear. These relations however are interesting and their possible consequences for the field of societal transitions and transition management possibly far reaching. The NLSA offers the opportunity to connect social development and the evolution of network topology.

In a second mode the NLSA can be used to simulate the reaction of the social system studied to outside developments. A good example of this type of application is the analysis of the influence of technological development on the direction and speed of social change. Technological development is often seen as a driving force for both the direction and speed of social development. Often the term technology push is coined in this realm. In the NLSA technology push can be implemented by setting a bias on the exchange module of the model, such that exchanges involving a specific issue are selected more often than other exchanges. This will possibly have consequences for 
both the speed and direction of these developments and possibly the occurrence of transitions. Although the hypotheses formulated above seem logical, its further analysis using the NLSA is not trivial. Because the dynamics of the NLSA resulting from the bias on the exchange module feeds back into the selection and mutation procedure for actors the simulation output is not easy to predict and probably sensitive to initial conditions and random disturbances. For example, if sustainable development is one of the issues included in the NLSA, the development of more sustainable alternatives to cars driven by fossil fuel, for example hydrogen cars, can result in an increase of the exchanges related to sustainable development. Based on our insight in the NLSA we conjecture that technological development will indeed direct social development in a specific direction and increase the speed of development in that direction. This hypothesis is based on the direct influence of technological development, in term of exchanges of control, in the NLSA. If a specific issue is more often involved in the exchanges of control, this is expected to have a direct effect on the total exchange of control related to the issue addressed by this new technology. It is however still a hypothesis because the influence of the feedback through selection and mutation of actors is difficult to grasp.

Changes in the preferences of actors are another example of a social development or trend that can influence the development of a specific social system. Again sustainable development is an interesting example. The question than is: Will the current surge in interest in sustainable development related to climate change, result in a more sustainable development? In the NLSA such a development should be signified by an increase in exchange of control related to the issue of sustainable development. Such a trend in the development of preferences can be simulated in the LSA by implementing a gradual increase in the interest in the issue of sustainable development. We hypothesize that changes in preference do not influence social development in a predetermined direction and will also not speed up the development of the social system in this more and more preferred direction. Firstly, because the increase in the interests is evenly distributed over all the actors, the possibilities for a 'double coincidence of wants' decreases because all actors basically become more and more interested in control over the same issue. Secondly, a trend in a specific preference does not influence the selection of exchanges of control in any predetermined direction. Again this hypothesis seems logical but is not trivial because of feedback mechanisms and possible sensitivity to initial conditions and random events.

Further use of the model can also focus on instruments of transition management (Loorbach 2007; Rotmans 2005). Important instruments of transition management are visioning (Rotmans 2005; Van der Brugge et al. 2005) and strategic niche management (Kemp et al. 1998). In transition management, visioning aims to adaptively develop shared problem perceptions and long term visions and goals to guide short term action (Loorbach 2007). For the NLSA this implies the convergence of interests of actors on the values adopted in the vision. Transition management hypothesis that such a convergence can result in a structural change, a transition, of the societal system considered. With the NLSA, such an instrument can be evaluated by implementing a convergence of the interest of actors on specific issues and analyzing the relation with both the speed and direction of social development and the occurrence of persistent change in the power and value structure of the NLSA. 
Strategic niche management aims to develop innovative alternative solutions for wicked problems in niches initially protected from the scrutiny of the market (Kemp et al. 1998). In the NLSA, alternatives are the carriers of exchange of control. The effect of more or less innovative condition on the exchange of control can be evaluated in the NLSA by increasing the opportunities for exchange of control and evaluate the resulting speed and direction of social development and the occurrence of structural change. It is especially interesting to see if a burst of innovations can eliminate a stable regime and push the societal system into transition resulting in a persistent change of its power and/or value structure.

A third promising application of the NLSA would be the co-evolutionary development of two or more social systems. This would require the development of coupled NLSA's. The coupling can be implemented in a number of ways. First actors can be exchanged between the NLSA's based on their self-dependence; second exchanges of control can be implemented in one of the systems only based on the magnitude of the exchange realized. And third, newly mutated actors can be incorporated in one of the systems based on their contribution to the potential for exchange of control in the respective NLSA's. This type of models could facilitate the simulation of synchronic development in two or more societal systems and operationalize the concept of co-evolutionary steering (Rotmans 2005; Kemp and Rotmans 2005; Rotmans et al. 2001). Furthermore the model can be used to evaluate more operational instruments of transition management, like the transition arena (Loorbach 2007).

\section{Conclusions}

Transitions are structural innovations of societal systems, transformations between two temporal (dynamic) equilibrium states. In between there is a period of rapid change during which the system undergoes irreversible re-organization (Rotmans 2005). The conceptualization of societal transitions in transition studies has much in common with a class of revolutionary change theories based on the punctuated equilibrium paradigm postulated by Eldtredge and Gould (Gould and Eldredge 1977; Eldredge and Gould 1972). In an overview article, Gersick confronts the Darwinian concept of incremental cumulative change with the punctuated equilibrium paradigm by comparing a range of theories on change from the social sciences (Gersick 1991). We started this paper by positioning transition science in this realm of revolutionary change theories.

In developing our computational approach to societal transitions, we focused on both the punctuated equilibrium dynamics of the output of such a model and the identification of structural change in terms of deep structure (Gersick 1991) and self organized criticality (Bak and Sneppen 1993). Our starting point is the Linear System of Action (Coleman 1990). In this paper a Non-linear System of Action (NLSA) is developed. The model is an extension of the Linear System of Action (LSA). While the LSA is an equilibrium model, the NLSA, through the addition of a variation and selection algorithm, is dynamic. The extension of the LSA is developed and motivated in line with the rational actor model underpinning the LSA. Furthermore the variation 
and selection procedure follows the finding by Bak and Sneppen, that in order to produce self organized critical behavior, the least fit actors should be selected for mutation (Bak and Sneppen 1993). In the NLSA, social development is reflected in the exchange of control.

The NLSA produces simulation results that mirror some of the main characteristics of transitions in a societal system. Both the frequency distribution of the exchanges of control and the length of the periods between two successive exchanges of control follow a power law distribution. These results prove that NLSA models with a size, number of actors times number of issues, exceeding 100, self-organize into a critical state. In this self-organized critical sate the NLSA shows punctuated equilibrium dynamics in which periods of limited exchange of control and stagnation and periods of high exchange of control, transitions, alternate. In this way the NLSA establishes a more formal relation between the metaphoric use of concepts from complex adaptive systems theory in transition theory (Rotmans 2005; Van der Brugge et al. 2005; Kemp et al. 1998), literature on policy development and agenda setting (Baumgarter and Jones 1993) and Kingdon (1984) and theories of self-organized criticality (Bak and Sneppen 1993; Bak et al. 1988).

In the NLSA, structural change is connected to a persistent change in its power or value structure. For transition science, especially the emergence of new power and value regimes in the NLSA is of interest. Our results show that persistent changes in the power structure of the NLSA occur and normally result from periods with relatively high exchange of control and are often followed by periods with exchange of control. No relation has been found between the emergence of new value regimes and the occurrences of exchanges of control.

The NLSA can be used to study societal change and social transitions in different modes. First, the model can be used as a simulation tool generating its own social development, characterized by the speed of development, the direction of the development and the emergence of new power or value regimes. In this realm also research on the dynamics of network structures and the evolution of network topology in the NLSA and the possible development of scale free networks and power law distributions of network components (Whitmeyer and Yeingst 2006; Albert and Barabási 2002) and self-organized networks (Bak 1996; Dorogovtsev et al. 2003; Jensen 1998) resulting in globally stable and locally instable social networks (Whitmeyer and Yeingst 2006; Watts 2002). Although these analyses are theoretical and their relation with societal transitions and transition management are still unclear, their empirical consequences and connectedness to real social networks seem promising. The results and insight gained from this type of studies primarily help us to better understand the dynamics of social systems and increase our insight in the conditions under which transitions are imminent.

In a second mode the model can be used to simulate the reaction of the social system studied to outside developments. Good examples of this type of application are the analysis of the influence of technological development and changes in the preferences of actors on the direction and speed of social change. In this mode the consequences of the current surge in interest in sustainable development for social change can be analyzed. Further use of the model can also focus on instruments of transition management like visioning (Loorbach 2007; Rotmans 2005; Van der 
Brugge et al. 2005) and strategic niche management (Kemp et al. 1998). Both can be implemented and studied with the NLSA.

In summary we conclude that the NLSA mirrors some important characteristics of societal transitions, is promising for its purpose of gaining insight in the dynamics of transitions and the evaluation and development of instruments and tools for transition management. Besides the model is flexible, allows for a connection to real world issues and is well embedded in sociological theory.

Open Access This article is distributed under the terms of the Creative Commons Attribution Noncommercial License which permits any noncommercial use, distribution, and reproduction in any medium, provided the original author(s) and source are credited.

\section{Appendix: The LSA and the calculation of equilibrium control}

In the LSA, there are two sets of elements, one referring to the decision makers $i$ $(i=1, \ldots, n)$ and the other to the issues $j(j=1, \ldots, m)$. Decision maker $i$ has control $c_{i j}$ over issue $j$ and interest $x_{j i}$ in issue $j$. Decision makers maximize utilities in accordance with a Cobb-Douglas-type utility function:

$$
U_{i}=c_{i 1}^{x_{1 i}} c_{i 2}^{x_{2 i}} \ldots c_{i m}^{x_{m i}},
$$

where $U_{i}$ is the total utility of decision maker $i, c_{i j}$ is the amount of control over issue $j$ held by decision maker $i$ and $x_{j i}$ expresses the contribution of this amount of control over issue $j$ to $U_{i}$. In the Cobb Douglas-type utility function, we have:

$$
\sum_{j=1}^{n} x_{j i}=1 \quad \text { and } \quad \text { all } x_{j i} \geq 0
$$

Let $C$ be the matrix of control, with entries $c_{i j}$ and let $X$ be the matrix of interest with $x_{j i}$. Both $X$ and $C$ are scaled arbitrarily and are normalized so that:

$$
\sum_{i=1}^{m} c_{i j}=1 \quad \text { and } \quad \sum_{j=1}^{n} x_{j i}=1 \quad \text { and } \quad x_{j i} \geq 0 \quad \text { and } \quad c_{i j} \geq 0 .
$$

The matrix of equilibrium control $C^{*}$, where the entry $c_{i j}^{*}$, stands for the equilibrium control of decision maker $i$ over issue $j$, can be calculated as $C^{*}=D_{r} X^{\prime} D v^{-1}$. The matrix $D_{r}$ is a diagonal matrix with elements $r_{i}$ and the matrix $D_{v}$ is a diagonal matrix with elements $v_{j}$.

The power vector $r$, with elements $r_{i}$, and the value vector $v$, with elements $v_{j}$, can be calculated as

$$
r=\left(I-C X+E_{n}\right)^{-1} e n_{1} \text { and } v=\left(I-X C+E_{m}\right)^{-1} e m_{1},
$$

where $E_{n}$ is a square matrix with elements $1 / n, E_{m}$ is a square matrix with elements $1 / m$ and the vectors $e n_{1}$ and $e m_{1}$ are defined as $n \times 1$ and $m \times 1$ columns from these matrices; $I$ is the identity matrix. 


\section{References}

Albert R, Barabási A-L (2002) Statistical mechanics of complex networks. Rev Mod Phys 74:47-97

Bak P (1996) How nature works: the science of self-organized criticality. Copernicus, New York

Bak P, Sneppen K (1993) Punctuated equilibrium and criticality in a simple model of evolution. Phys Rev Lett 71(24)

Bak P, Tang C, Wiesenfeld K (1988) Self-organized criticality. Phys Rev Lett A 38:364-374

Baumgarter FR, Jones BD (1993) Agenda's and instability in American politics. University of Chicago Press, Chicago

Beroggi GEG (1999) Decision modeling in policy management. Kluwer, Dordrecht

Beroggi GEG (2000) An experimental investigation of paired-comparison preference elicitation methods. J Multicriteria Decis Anal 9:2-3

Castells M (1996) The rise of the network society. Blackwell, Oxford

Coleman JS (1986) Individual interests and collective action: selected essays. Cambridge University Press, Cambridge

Coleman JS (1990) Foundations of social theory. The Belknap Press of Harvard University Press, Cambridge

Crozier M, Friedberg F (1980) Actors and systems: the politics of collective action. University of Chicago Press, Chicago

Davis K (1945) The world demographic transition. Ann Am Acad Polit Soc Sci 237:1-11, World population in transition

Dorogovtsev SN, Mendes JFF, Samukhin AN (2003) Metric structure of random networks. Nucl Phys B 653(3):307-338

Eldredge N, Gould S (1972) Punctuated equilibria: an alternative to phyletic gradualism. In: Schopf TJ (ed) Models in paleobiology. Freeman, Cooper \& Co, San Francisco

Field S, Witt J, Nori F (1995) Superconducting vortex avalanches. Phys Rev Lett 74:1206-1209

Fiol MC, Harris D, House R (1999) Charismatic leadership strategies for effecting social change. Leadersh Q 10(3):499-482

Geels F, Kemp R (2000) Transities van uit Socio-Technisch Perspectief (Transitions from a socio-technical perspective). Maastricht, The Netherlands

Gersick CJG (1991) Revolutionary change theories: a multi-level exploration of the punctuated equilibrium paradigm. Acad Manage Rev 16(1):10-36

Gould SJ, Eldredge N (1977) Punctuated equilibria: the tempo and mode of evolution reconsidered. Paleobiology 3(2):115-151

Hechter M (1987) Principles of group solidarity. University of California Press, Berkeley

Hechter M (1988) Rational choice foundations of social order. In: Turner JH (ed) Theory building in sociology. Sage, Newbury Park

Held GA, Solina DH, Solina H, Keane DT, Haag WJ, Horn PM, Grinstein G (1990) Experimental study of critical-mass fluctuations in an evolving sand pile. Phys Rev Lett 65:1120-1123

Jaeger HM, Liu C-H, Nagel SR (1989) Relaxation at the angle of repose. Phys Rev Lett 62:40-43

Jensen HJ (1998) Self-organized criticality: emergent complex behavior in physical and biological systems. Cambridge University Press, Cambridge

Jones BD, Baumgartner FR (2005) A model of choice for public policy. J Public Adm Res Theory 15(3):325-351

Kemp R, Rotmans J (2005) The management of the co-evolution of technical, environmental and social systems. In: Weber M, Hemmelskamp J (eds) Towards environmental innovation systems. Springer, New York, pp 33-55

Kemp R, Schot J, Hoogma R (1998) Regime shifts to sustainability through processes of niche formation: the approach of strategic niche management. Technol Anal Strateg Manag 10:175-196

Kingdon JW (1984) Agenda's, alternatives, and public policies. Little Brown, Boston

Lewin K (1995) 1951 Field theory in social science. Harper and Row, New York

Loorbach D (2007) Transition management new mode of governance for sustainable development. International Books, The Netherlands

Martens P, Rotmans J (2005) Transitions in a globalising world. Futures 37(10):1133-1144

Nash JF Jr (1950) The bargaining problem. Econometrica 18:155-162

Pappi FU, Knoke D (1991) Political exchange in the German and American labour policy domains. In: Marin B, Mayntz R (eds) Policy networks, empirical evidence and theoretical considerations. Campus Verlag, Frankfurt am Main 
Plourde B, Nori F, Bretz M (1993) Water droplet avalanches. Phys Rev Lett 71:2749-2752

Rotmans J (2005) Societal innovation: between dream and reality lies complexity. Inaugural Address, Erasmus University Rotterdam

Rotmans J, Kemp R, van Asselt M (2001) More evolution than revolution: transition management in public policy. Foresight 03(01): 17

Scott J (2000) Social network analysis. A handbook. Sage, London

Schouten MJ, Timmermans JS, Beroggi GEG, Douven WJAM (2001) Multi-actor information system for integrated coastal zone management. Environ Impact Assess Rev 21:271-289

Schumpeter JA (1934) The theory of economic development: an inquiry into profits, capital, credit, interest and the business cycle. Harvard University Press, Cambridge

Sebenius JK (1992) Negotiation analysis: a characterization and review. Manage Sci 38(1):18-38

Smith A, Stirling A, Berkhout F (2005) The governance of sustainable socio-technical transitions. Res Policy 34(10):1491-1510

Stokman FN, Berveling J (1998) Dynamic modeling of policy networks in Amsterdam. J Theor Polit 10(4):577-601

Stokman FN, Zeggelink EPH (1996) Is politics power or policy oriented? A comparative analysis of dynamic access models in policy networks. J Math Soc 21(1-2):77-111

Tamarit FA, Cannas SA, Tsallis C (1998) Sensitivity to initial conditions in the Bak-Sneppen model of biological evolution. Eur Phys J B-Condens Matter Complex Syst 1(4)

Timmermans JS (2004) Purposive interaction in multi-actor decision making operationalizing Coleman's linear system of action for policy decision support. Eburon, Delft

Timmermans JS, Beroggi GEG (2000) Conflict resolution in sustainable infrastructure management. Saf Sci 35(1-3):175-192

Timmermans JS, Beroggi GEG (2004) An experimental assessment of Coleman's linear system of action for supporting policy negotiations. Comput Math Organ Theory 10:267-285

Turner JH (1998) The structure of sociological theory, 6th edn. Wadsworth Publishing Company, Belmont

Van der Brugge R, Rotmans J (2007) Towards transition management of European water resources. Water Resour Manag 21:249-267

Van der Brugge R, Rotmans J, Loorbach D (2005) The transition in Dutch water management. Regional Environmental Change 5(4)

Watts DJ (2002) A simple model of global cascades on random networks. Proc Natl Acad Sci 99(9):57665771

Weber M (1958) [1904] The protestant ethic and the spirit of capitalism. Scribner's, New York

Whitmeyer JM, Yeingst CN (2006) A dynamic model of friendly association networks. Soc Sci Res 35(3):642-667

Worren NAM, Ruddle K, Moore K (1999) From organizational development to change management: the emergence of a new profession. J Appl Behav Sci 35(3):273-286

Jos Timmermans obtained his PhD from the school of Policy Analysis and Management of Delft University of Technology. He is currently employed as researcher and consultant with the Dutch Research Institute for Transitions of Erasmus University Rotterdam. He works from the punctuated equilibrium paradigm and his research interests include stakeholder analysis, policy entrepreneurship and social network theory. 